\title{
Components of the power balance consumption and their influence on the procedure of competitive power selection UES of Russia
}

\author{
Yurii Chukreev ${ }^{1, *}$, Mikhail Chukreev ${ }^{2}$ \\ ${ }^{1}$ Institute for Socio-Economic \& Energy Problems of the North Federal Research Center of the Komi Science Centre \\ of the Ural Branch of the Russian Academy of Sciences, Syktyvkar, Russia \\ ${ }^{2}$ Institute for Socio-Economic \& Energy Problems of the North Federal Research Center of the Komi Science Centre \\ of the Ural Branch of the Russian Academy of Sciences, Syktyvkar, Russia
}

\begin{abstract}
The impact of the time aspect in planning of the maximum load and the standard capacity reserve on determination of the price for the power capacity while the competitive power selection procedure is described. The article illustrates the fundamental differences between the concepts of the load forecasting error caused by the temperature factor and forecast volume of power consumption, considering it in power capacity demand formation. The results of the impact made by these factors on the competitive power selection procedure are presented.
\end{abstract}

\section{Introduction}

The current state of the electric power industry is characterized by the significant excess of the generating capacity caused by the reduction in electricity consumption during the restructuring period. This significantly reduces efficiency of the industry and does not contribute to its development by constructing new generating sources. Long-term power contracts (LTC) mechanism on the power capacity in the competitive capacity selection procedure (CSP) provides implementation of the new generation sources in the power balance mainly by increasing power charges to consumers by various means of increasing the projected demand parameters in the power balance. From these points of view, the article deals with formation of the components of the power demand - the maximum load and the normative power reserve in the normativetechnical documents (NTD).

\section{Peculiar features of a competitive power capacity selection}

The competitive selection procedure, conducted on the JSC «SO UES» site determines the paid power capacity on the wholesale market from its existing excess volume. It is thus also aimed at identifying ineffective generators in order to reduce the existing excess of power capacity in the UES Russia. The power, which has not been selected, is not paid and therefore must be de-installed if approved by the Ministry of Energy of the Russian Federation. Thus, in accordance with the NTD, approved by the RF Government
Resolution № $893^{1}$ (hereinafter RF GR № 893) the new rules while CSP for the mandatory charge for the power capacity:

- contracts on generation of the power capacity by the new power stations generators (NLTC);

- generating units whose work is necessary to support the technological regimes of the power system or the supply of thermal energy (forced generators - FG).

Selection of the efficient generators for power stations while providing CSP is based on the costdependent supply of the generating capacity and capacity demand (fig. 1). This relationship is a line segment through two points (in fig. 1 - points 1 and 2). In the first point, the demand for power is determined by the Regulation approved by the Ministry of Energy of Russia $^{2}$ (hereinafter Regulation № 431). In the second, it increases by $12 \%$. At that, it is important that the price of the power capacity at the designated points could not be changed and is set by the Government of the Russian

\footnotetext{
${ }^{1}$ Resolution of the Government of the Russian Federation dated on August 27, 2015 № 893 «On the amendment and recognition of certain acts of the Government of the Russian Federation on the functioning of the wholesale market of electrical energy and power capacity, as well as provision of the long-term competitive power selections».

${ }^{2}$ Regulation on how to measure the capacity demand for the long-term competitive power selections at the wholesale market of the electric power (power capacity) and the procedure of determining the planned coefficients for the reserve of power capacity in zones (groups of zones) for the free flow of electrical energy (power capacity) approved by the Ministry of Energy of the Russian Federation dated on 07.09.2010 № 431 (edit. on 17.08.2017).
} 
Federation on the price level of 2017, indexed in temperatures. The normative (full) power capacity

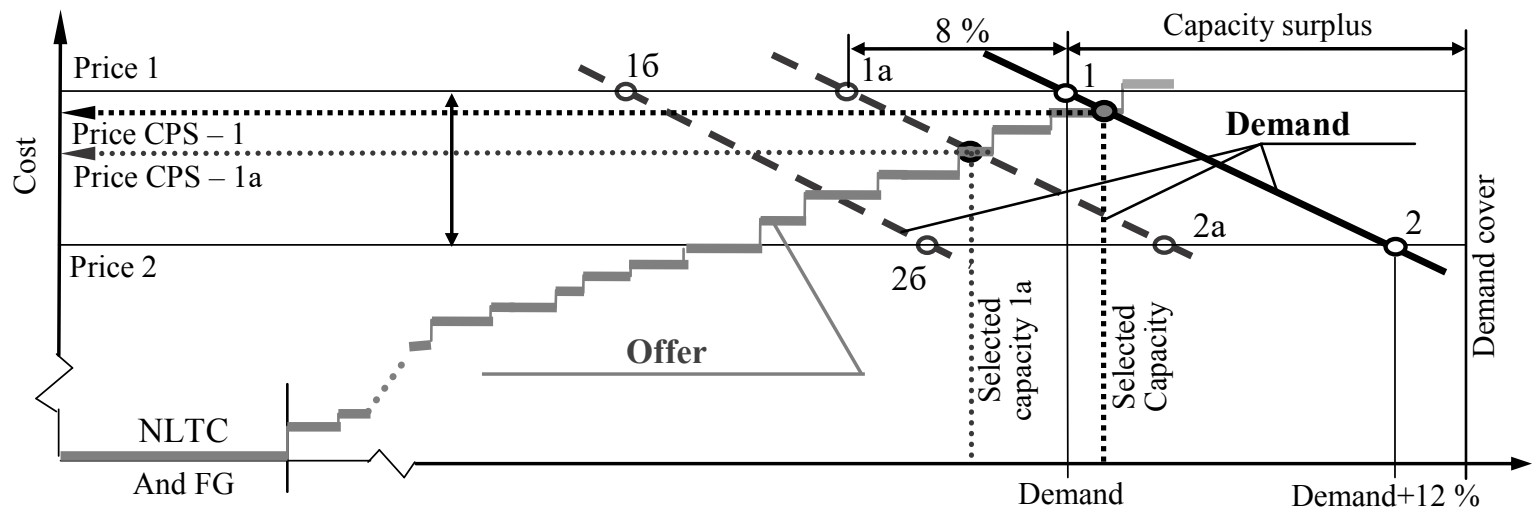

Fig. 1. To explain the commercial power selection procedure.

accordance with the consumption price index and a possible increase of up to $20 \%$ approved by the Ministry of Energy of Russia.

Impact of the power capacity price from the CSP on power demand is shown in Fig. 1. In addition to the main demand dependence (a solid line in bald 1-2), there are two more (dotted lines $1 \mathrm{a}-2 \mathrm{a}$ and $1 \mathrm{~b}-2 \mathrm{~b}$ ) for the reduced capacity demand by $8 \%$. In fig. 1 , it is obvious that the only way to improve investment attractiveness for NLTC implementation is to increase the capacity demand component. The offer supply profile (a grey broken line) is determined by the energy companies and should not depend on the declared capacity demand.

\section{Capacity balance of the UES Russia}

The rationale for the generating sources in managing development of the UES Russia depends, in one way or another, on the planned magnitude of the maximum loads. The latter, as we all know, are formed in the perspective power balances (fig. 2). This information in accordance with the RF Government Resolution ${ }^{3}$ since 2010 is annually formed in the work "Scheme and programme for development of the UES of the country for a 7-year period» (SPD of the UES). The expenditure side of the balance is determined by the capacity demand and comprises three components: the projected maximum load, power capacity export/import and the normative capacity reserve. The revenue side of the balance is determined by the installed power capacity of generators at power stations minus various types of capacity limits on maximum load, power output after passing the maximum load, and power not released (locked). In a balanced variant, the coverage of the demand of the input part shall correspond to the demand for the power-balancing capacity.

The planned maximum load is formed on the basis of the projected power consumption over the territories of the constituent entities of the Russian Federation, taking into account the average multi-year ambient air

\footnotetext{
${ }^{3}$ Rules for development and approval of the schemes and programs for the future development of the electric power industry, approved by the Resolution of the Government of the Russian Federation dated on 17.10.2009 № 823 .
}

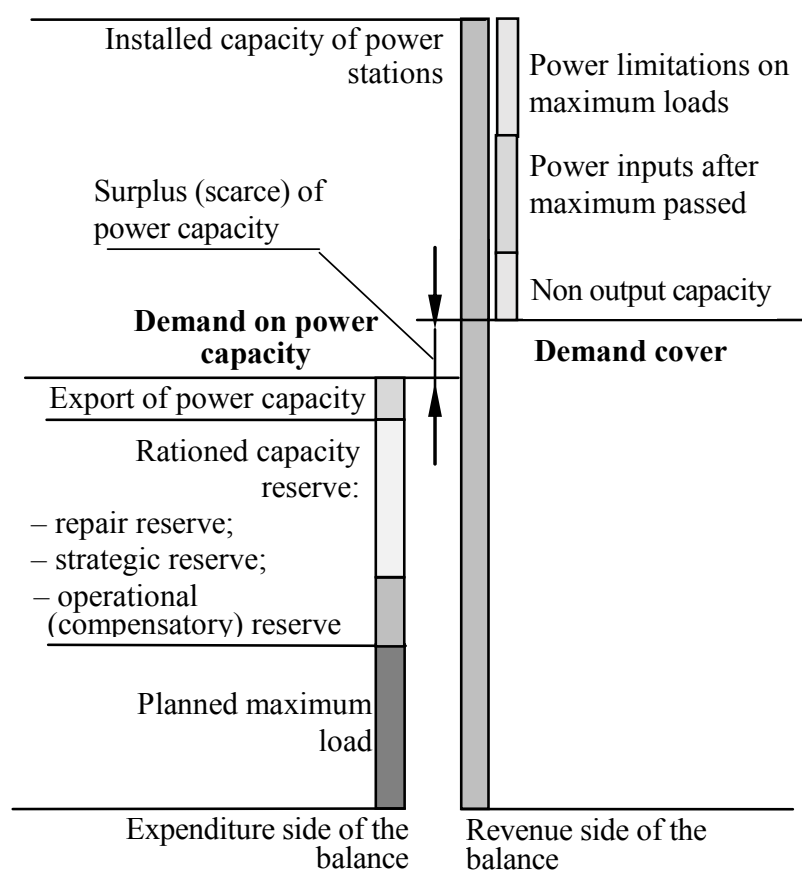

Fig. 2. Structure of the projected power balance.

reserve includes the components of the operational (recently called compensational), maintenance and strategic capacity reserves.

\section{Submission of the load when justifying the normative power capacity reserve}

Rationale for the reliability providing tools deal with development of the balance reliability indicators estimation models (BRI), which take into account both the detailed balance of power and a number of random factors caused by the unreliability of equipment and the uncertainty of the projected parameters. The operational component of the regulatory reserve of power is mainly due to two random factors: the unplanned repairs of the generating equipment and random variations in load caused by the temperature factor.

The first one was called the emergency component of the operational reserve of capacity; the second one was 
called load-bearing [1]. Their contribution to the total operating reserve depends on the specific information. According to the researches [1], when using the information used in the development of MR made in 2003 (norms for equipment safety and routine maintenance standards), the amount of the load reserve is more than $40 \%$ of the operating power capacity reserve or more than $4 \%$ of the combined maximum load. Major repairs of equipment in this case were not considered due to the assumption that they would fit into the seasonal load failures. That was in fact the reason for the December timetable, which would be described below. It should be noted that taking into account the correlation of occasional load changes in the territorial zones of the UES Russia [2], the share of the load reserve increases up to $60 \%$ of the operational reserve of power capacity or more than $6 \%$ of the maximum load.

The practical application of models for justification of reservation tools were described in the NTD - the methodological recommendations (MR) for projecting of development of the power systems with information on the regulatory values of reserve capacity in territories in the form of the united EES. The last revision of such a MR was done in the mid-1990s of the last century [3, 4]. The Ministry of Energy of Russia approved it only in 2003.

Submission of the load in estimating BRI and determining the means of its provision - capacity reserves is based on the use of average daily load schedules over the working days of the annual December maximum in the power system (fig. 3). This schedule is expected to run for all working days of the year (250 days).

This is a fairly substantial simplification of the electricity consumption regime, which significantly affects the value of the adopted balance sheet reliability standard $\left(\rho=1-J_{\text {д }}=0,996\right)[1,5,6]$. This presentation of the annual load change schedule at that time was justified

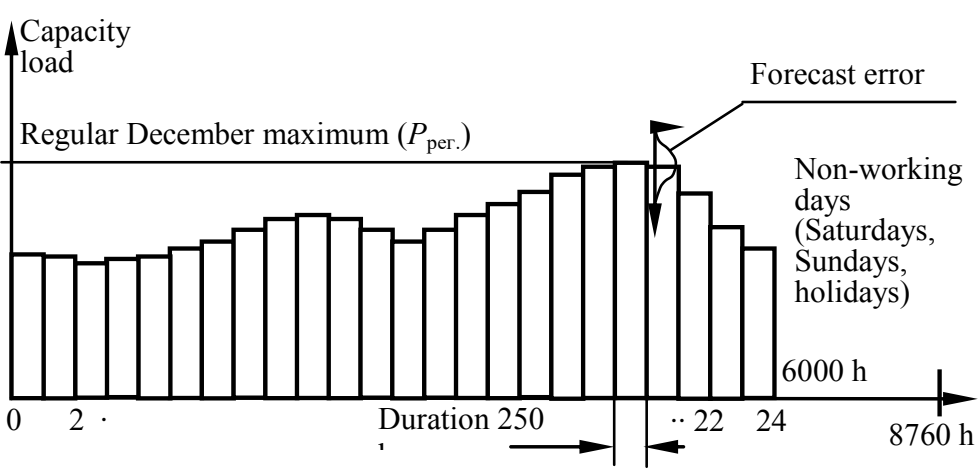

Fig. 3 - Submission of the annual electrical consumption mode, typical daily schedule of December month.

also due to the hypothesis of inscribing the «site» necessary for carrying out the planned repairs in the seasonal reduction of loads. Today, some researchers and specialists are trying to use this standard when using other pressure modelling techniques, which is unacceptable $[5,7]$. When considering the hourly load schedule for the whole calendar year, it is necessary to use the European safety standard [8]. The regulatory value of the European standard for probable power deficit hours $L O L H=3 \div 8$ hours is being transformed for the value accepted in Russia $\rho=1-(3 \div 8) / 8760 \approx 0$, $9997 \div 0,9991$.

The electrical consumption mode in the existing balance-sheet reliability models $[1,6,9]$ is characterized not by the planned maximum load $\left(P_{\text {план. }}\right)$ as in the power balance, but by the regular annual maximum $\left(P_{\text {per. }}\right)$ and random values $\left(\sigma_{\Pi}\right)$ of the non-observed deviations. The maximum $\left(P_{\text {план. }}\right)$ and regular $\left(P_{\text {рег. }}\right)$ maximum loads are in general terms incompatible (fig. 4), one is planned, the other is the result of the processing of the huge spectrum of retrospective information on the real electric consumption modes in order to obtain information for the BRI estimation models - the regular average value $\left(P_{\text {рег. }}\right)$ and the random deviations from it $\left(\sigma_{\Pi}\right)$, caused by the weather conditions.

Analysis of the retrospective information on load changes caused by the temperature factor shows that it could be described by the normal distribution law [2]. When validating reserve funds, but not estimation of the BRI, it is important how the application of the planned or regulatory maximum in the models affects the percentage of the normative reserve power. The conducted researches [6] have revealed a small, less than 0.1 per cent impact of the combined maximum for all territorial zones of the UES Russia. This allows to apply in the justification models of the reserved fund the planned maximum load rather than the regular one, with the occasional changes in load due to the temperature factor (fig. 4, a dotted curve).

Currently, the processes for obtaining the initial information on electricity consumption levels and schedules of their changes significantly differ from those existed while the NTD were developed. Nowadays it is possible to obtain the real graphs of changes in loads on the UES Russia power systems in any period due to digitalization of information:

- within a retrospective period of actual power at the

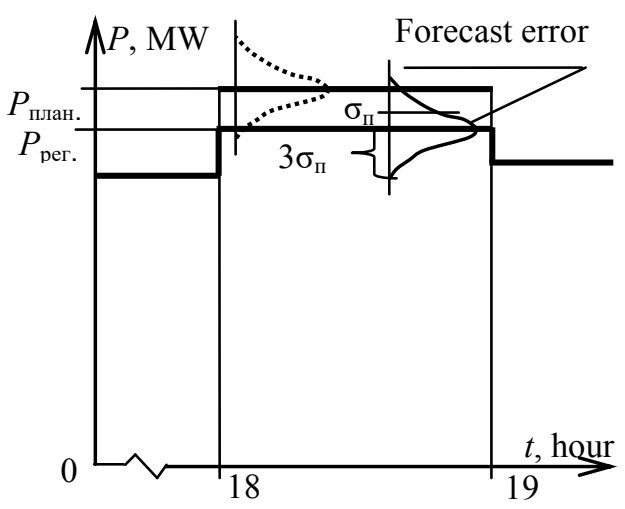

Fig. 4-Towards the concept of the planned and regular maximum load. end of the hour ${ }^{4}$; actual average daily and monthly temperatures; actual annual electrical energy consumption;

\footnotetext{
${ }^{4}$ Daily dispatch reports of the operational information complex (OIC) of the chief dispatching center of the JSC «SO UES».
} 
- within the projection period of annual electricity consumption as defined in the works SPD of the UES Russia.

Availability of this information allows the creation of the required data package for the existing software in order to solve the balance-sheet reliability problem. It includes:

1) a form of the projected average daily graphs of loads;

2) random load deviations from mean values;

3) regular load maximum values.

Obtaining the listed parameters in regards of the BRI software evaluation is given in [2].

\section{Analysis of a power consumption forecast}

The value of the planned maximum load is the basis of the capacity demand of the power consumption part of the power balance. Hence, the errors in forecasting this value have a significant impact on the justification of the generating capacity of the contributing countries to cover the power balance. Taking into account these circumstances, the JSC «SO UES» has created a unified system for forecasting the production and consumption of electricity and power for the period of 7 years. Power consumption forecast is developed for the hour of maximum in December for the average daily temperature of its maximum consumption averaged 10 years prior to autumn and winter. At that, it takes into account the actual capacity balances of the previous periods, plans for the technological integration of facilities and macroeconomic indicators in accordance with the country's socio-economic development scenarios.

In fig. 5 for the period of 2016-2019, there is information on the percentage deviations of the projected maximum load parameters (from the work SPD of the UES Russia) from the actual values for the price zones in the European part of the UES Russia and Siberia. Consideration before 2016 is not possible due to lack of information in works of SPD of the UES
Russia, it starts with 2016 and provides a forecast for the period of 7 years. Review of information on the actual power consumption since 2019 is not possible due to the lack of information. In fig. 5, dotted lines: 2 - average deviations over a 4-year retrospective period from actual values, thinner lines 3 - their maximum and minimum bypassing.

The bold line 1 shows the change in actual load maximums from their mean value from 2013 to 2019. It can be seen that for both price zones there is a practical discontinuity of the consumption growth, which does not in any way correlate with its forecasts.

It is obvious that if the forecasted period increases for both price zones, deviations significantly go up. It should be noted that, the recent works of SPD of the UES Russia such deviations decrease to the reasonable levels. However, a systematic error in forecasting for the first year (from 2 to $3 \%$, fig. 5) remains. For example, in the works of SPD of the UES Russia for the period of 2011-2017 the gap between the planned maximum load for the first and seventh years was $17.65 \%$ for the European part of the UES Russia, and $17.56 \%$ for the UES of Siberia. In the work carried out in 8 years, on the planning horizon 2019-2025, the gap significantly narrowed to $5.7 \%$ and $8.53 \%$ in accordance. Based on the above analysis, it can be assumed, that in justifying the generating capacity in the CSP the deviations of the projected for the 7-years period parameters of the max load, taking into account their systematical deviation on one projected year of the actual values should make minimum 5\% for the first price zone and $10 \%$ for the second zone.

\section{Components of the power capacity demand in the scientific and technical documents while the CSP}

In accordance with the Regulation № 431 the capacity demand for the year of the CSP is determined by three components: planned, taking into account the impact of the temperature factor combined with the maximum load, the planned reserve ratio and the

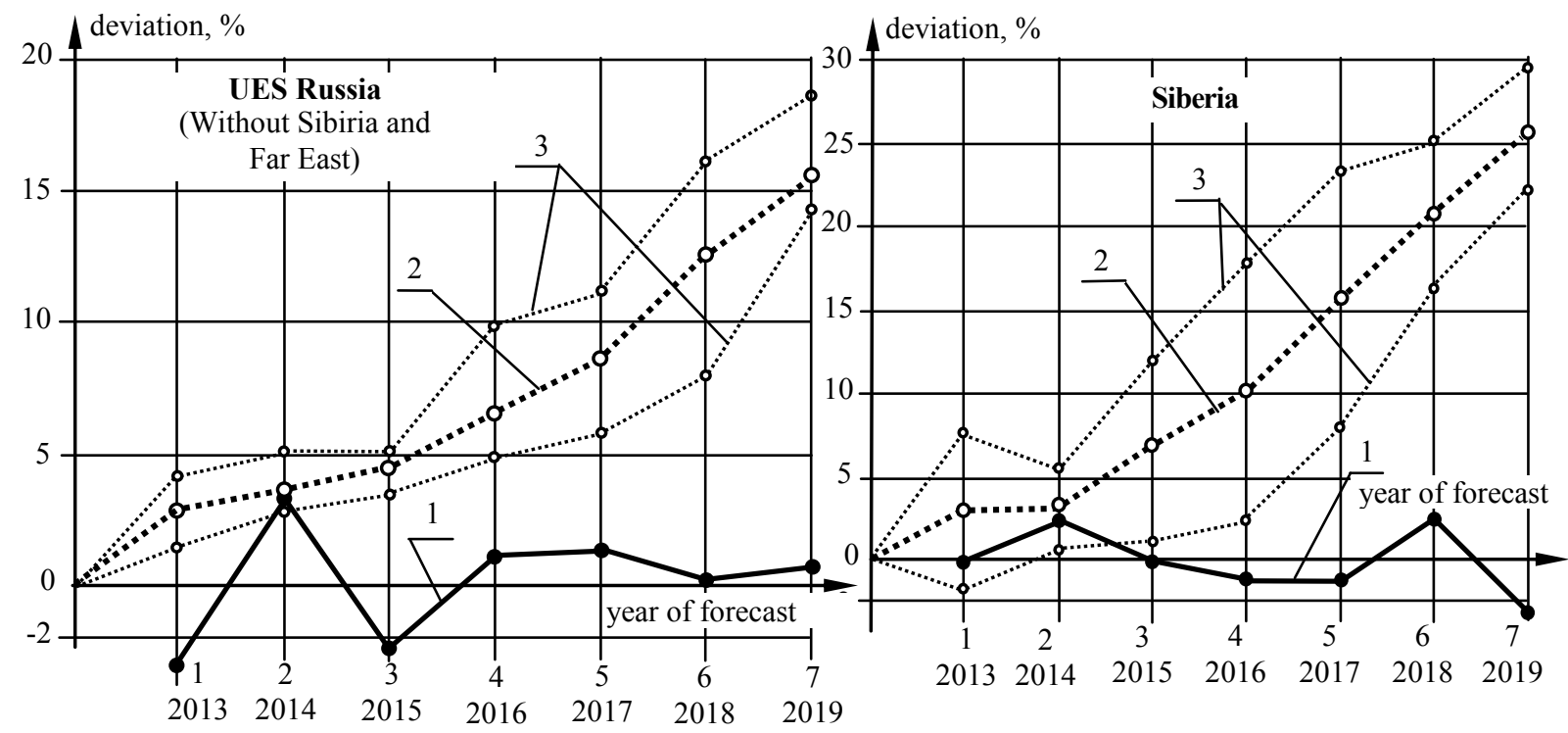

Fig. 5. Deviation of the forecast loads (with a high probability of implementation) from the actual meanings for the UES Russia without UPS Far East and Siberia (from 10 issues of the SPD from 2010 - 2016 until 2019 - 2025). 
planned maximum consumption in retail markets. As a result, the demand for power is determined by multiplying the planned combined maximum load, taking into account the effect of the temperature factor on the planned reserve coefficient minus the planned generation of electrical energy in the retail markets.

The planned combined maximum load is determined by the forecast presented in the works of SPD of the UES Russia, increased by the coefficient caused by the temperature factor. Its value in information generation for the CSP for the period of 2022-2024 and 2025 for both price zones exceeds $4.2 \%$ of the combined maximum. The influence of the temperature factor shall also be taken into account when justifying the normative reserve of power (see sector 3 ). Thus, the Regulation № 431 has a double counting of the same factor, leading to an increase in the power demand by at least $4 \%$.

In the Regulation № 431, the value of the planned reserve ratio is determined by the sum of the coefficient of 1.17 , the coefficient of forecast underutilization of power and the coefficient taking into account the export of electrical energy. Coefficient 1.17 corresponds to $17 \%$ of the normative reserve of power from the planned combined maximum load given in the MR issued in 2003 for the European part of the UES Russia. For the UES Siberia this percent in the MR issued in 2003 makes only $12 \%$. In the Regulation № 431, the coefficient of 1.17 has been extended to the UES Russia as a whole for unexplained reasons. It is difficult to explain the reason for the increase in the 1.17 by the coefficient of the projected power underutilization that considers the power capacity reduction caused by the unscheduled repairs of the generating equipment. Unscheduled repairs have always been the basis for the justification of this very factor of 1.17 .

In our view, the substantive differences in the two considered NTDs are related to the incompetence of the experts who prepared the Regulation № 431. For its preparation in 2010 and its subsequent revision made in 2017 specialists of the academic and university science, as well as the sectoral Institutions, who are familiar with the issues of balancing reliability of EES, were not involved.

\section{Practical results and some conclusions}

The period of pre-emption when making the CSP is continuously growing. While prior to 2015 the CSP was conducted only 1 year in advance, for the next years the period of pre-emption was continuously increasing. In 2015, the CSP was conducted for the period of 20162019. From 2016 until 2018 for a year, that is three calendar years after. In 2018 for the period of three years at once (2022-2024). Moreover, finally, in the beginning of 2019 the CSP was conducted for 2025, in 2020 it is conducted for 2026, etc. With the increase of the pre-emption period, the error in the plan of the maximum load also grows, that enhances the investment component for the implementation of LTC of the new generators in the CSP procedure and is described in the RF Government Regulation № 893.
In accordance with the Regulation № 431, power demand is determined by the amount of the combined maximum load and the value of the planned reserve coefficient. Analysis, provided in section 4, reveals that the value of the combined maximum load increases with the growth of the pre-emption period. At that, this increase is not connected with the analysis of the retrospective information on changes in actual parameters. Taking into account the analysis of the retrospective information (section 4) and power balances given in the works of SPD of the UES Russia for the period of 2019-2025, it could be stated that an extension of the pre-emption period from three years to seven years would result in at least a 4-per cent increase in the maximum load in both price zones of the UES Russia. To this should be added the non-conformity of the NDT in the frame of the Regulation № 431 and MR of 2003 with regard to the cold season temperature factor. Thus, an extended period of pre-emption during the CSP and discrepancies between different NDS result in at least $8 \%$ reduction in the power capacity demand.

In early 2020, the CSP was conducted for the year $2025^{5}$, where the combined maximum load was 127 $547 \mathrm{MW}$. With a three-year pre-emption period, the required information for providing the CSP for the year 2025 was to be created in 2023. According to the above analysis, the combined maximum load for the 1-st price zone would be 122,640 MW and not 127,547 MW. As can be seen, the increase in the combined maximum load when the pre-emption period changed from 3 to 7 years was $5.86 \%$.

While making the CSP in 2020 for the year of 2025 the planned reservation factor was adopted, taking into account the random component of the temperature factor action of $18.4 \%$ of the combined maximum load, and the output capacity of the retail generation of $7143 \mathrm{MW}$. The capacity demand, if the temperature factor is not taken into account in the combined maximum load (this is included in the power capacity reserve) would be equal $138064 \mathrm{MW}(122640 \times 1,184-7143)$. This is $8 \%$ less than suggested by the CSP for the year 2025. That makes 30 bln rub in the money equivalent.

The given figure in section 1 illustrates the results of the decline by $8 \%$ in the planned demand on the power capacity. First, it is the reduction of cost for the power capacity, and hence the profitability of the generating companies and then reduction of the investment attractiveness for the new equipment. Second and equally important, there is an increase in excess capacity, unpaid by the consumers and requiring additional maintenance costs. The issues of dismantling of the equipment are not welcomed either by the JSC «SO UES» or by the generating companies, and even the Ministry of Energy of Russia is extremely reluctant to do so.

\footnotetext{
${ }^{5}$ Website of the JSC «SO UES» « Competitive power capacity selection », monitor.so-ups.ru
} 


\section{References}

1. Chukreev Yu.Ya. Modeli obespecheniya nadyozhnosti elektroenergeticheskikh system. Syktyvkar: Komi SC UrO RAN, 1995,176 p.

2. Chukreev Yu.Ya., Chukreev M.Yu., Chuprov V.S. Kharakhteristiki rezhima elektropotrebleniya primenitelno $\mathrm{k}$ zadacham balansovoy nadezhnosti pri upravlenii razvitiem elektroenergeticheskikh sistem rezultaty // Metodicheskiye voprosy issledovaniya nadyezhnosti bolshikh system energetiki. Irkutsk: Izdatel'stvo ISEM CO PAH, 2017, Issue. 68, p. 328-337.

3. Metodicheskie rekommendatsii po proektirovaniyu razvitiya energosystem. (Utverzhdeno Prikazom Minenergo Rossii ot 30 June 2003, № 281). M.: Minenergo RF, CO 153-34.20.118-2003.

4. Volkenau I.M., Zeiliger A.N., Khabachev L.D. Ekonomika formirovaniya elektroenergeticheskikh sistem. M.: Energoatomizdat, 1981, 320 p.

5. Markovich I.M. Rezhimy energeticheskikh sistem. M.: Energiya, 1969, 351 p.

6. Chukreev Yu.Ya., Chukreev M.Yu. Modeli otsenki pokazateleyi balansovoyi nadezhnosty pri upravlenii razvitiem elektroenergeticheskikh system. Syktyvkar: Komi SC UrO RAN, 2014, 207 p.

7. Chukreyev Yu., Chukreyev M., Stepskov A. The substantiation of regulatory requirements to the reliability of consumer support in the conditions of the perspective planning of the UPS of Russia // E3S Web of Conferences 25, Volume 58 (2017) Rudenko international Conference "Methodological Problems in Reliability Study of Large Energy Systems" (RSES 2018), Irkutsk, Russia, july 2-7, 2018. https://doi.org/10.1051/e3sconf/20185802002

8. Billinton R., Allan R.N. Reliability Evaluation of Power Systems. Second Edition. New York and London, Plenum Press, 1996, 509 p.

9. Kovalev G.F., Lebedeva L.M. Nadyezhnost' system elektroenergetiki. Novosibirsk: Nauka, 2015, 224 p. 